\title{
СОЦИАЛЬНЫЙ КАПИТАЛ КАК ИНСТРУМЕНТ ОГРАНИЧЕНИЯ ОППОРТУНИСТИЧЕСКОГО ПОВЕДЕНИЯ НА РЫНКАХ ДОВЕРИТЕЛЬНЫХ БЛАГ
}

\author{
М. А. Колосова, И. В. Скоблякова \\ Орловский государственный университет имени И. С. Тургенева
}

Поступила в редакцию 25 ноября 2019 г.

\begin{abstract}
Аннотация: рассматривается роль социального капитала в качестве инструмента ограничения оппортунизма субъектов рынка доверительных благ. Авторами теоретически обосновывается эффективность социального капитала на рынках с высокой степенью неопределенности, изучается структура социального капитала, выделяются уровни деперсонифицированного и персонифицированного доверия, определяются субъекты и направления (инструменты) формирования деперсонифицированного и персонифицированного доверия на современных рынках доверительных благ.
\end{abstract}

Ключевые слова: социальный капитал, рынок доверительных благ, оппортунистическое поведение, доверие, государство.

\begin{abstract}
: the article is devoted to the study of the role of the article is devoted to the study of the role of social capital as a tool to limit the opportunism of the subjects of the market of credence goods. In the first part of the article the authors theoretically substantiate the effectiveness of social capital in markets with a high degree of uncertainty, studied the structure of social capital, highlighted the levels of depersonalized and personalized trust. The second part of the article is devoted to the definition of subjects and directions (tools) of formation of depersonalized and personalized trust in the modern markets of credence goods.
\end{abstract}

Key words: social capital, market of credence goods, opportunistic behavior, trust, government.

Ориентация современных индивидов на максимизацию индивидуальной полезности, социальная напряженность, постепенный отказ от духовных ценностей в пользу материальных составляющих способствуют формированию в обществе эгоистического способа мышления и распространению недобросовестных схем взаимодействия. Это находит подтверждение в стремительном и массовом проявлении в обществе оппортунистической модели поведения.

Явление оппортунизма представляет собой стремление индивида реализовать эгоистический институциональный интерес к трансакционной деятельности, не ограниченной моральными устоями, по отчуждению и присвоению прав собственности при помощи искажения информации, с нанесением материального и морального ущерба другим лицам [1].

К характеристикам оппортунистического поведения относятся:

- несовпадение интересов экономических агентов;

- информационное преимущество одних агентов относительно других за счет наличия у них информации;

(С Колосова М. А., Скоблякова И. В., 2020
- рыночное преимущество отдельных субъектов за счет специфичности актива, человеческого капитала, наличия доступа к благам или ресурсам;

- преднамеренный характер поведения, выраженный в осознанном порядке действий оппортунистически настроенных агентов;

- перераспределение богатства за счет отчуждения индивидуального богатства (части богатства) одного субъекта в адрес другого субъекта;

- реализация намерений путем действий или бездействий агента [2-4].

Оппортунистическая модель поведения формируется под воздействием факторов, определяющих мотивы и стимулы экономических агентов, и реализуются при наличии соответствующих рыночных условий.

Рынок доверительных благ представляет собой хозяйственную структуру, объектами которой выступают блага, трансакции в отношении которых сопровождаются серьезными информационными несовершенствами за счет присущих им скрытых и многомерных характеристик, что влечет стабильное информационное преимущество субъектов предложения на всех этапах рыночной сделки, а субъективность потребительских оценок полезности доверительных благ обусловлена персонифи- 
цированным характером восприятия их качества $[5$, с. $174 ; 6$, с. 154$]$.

Потребительская неопределенность как ключевая проблема рынка доверительных благ влечет риск неблагоприятного отбора и высокие потери потребителей, что обусловливает «особый» характер потребительского спроса, высокие трансакционные издержки потребителей и участие посредников в процессе рыночного выбора.

Высокая индивидуальная и общественная значимость доверительных благ, вынужденный неэластичный характер спроса, отсутствие возможности самостоятельного выбора и качественная неопределенность на рынках доверительных благ свидетельствуют о наличие крайне «благоприятных» условий для формирования оппортунистических настроений хозяйствующих субъектов.

Экономическая политика ограничения оппортунизма на рынках доверительных благ предполагает развитие институтов ограничения оппортунизма и совершенствование направлений социальноэкономической политики государства. Однако данные меры не позволяют в полной мере справиться с проблемой оппортунизма до тех пор, пока мышление и поведение рыночных игроков продиктовано антагонистическими мотивами.

С целью борьбы с оппортунизмом современному обществу необходимо естественным путем отказаться от подобной модели поведения, а для этого необходимо сформировать отношения и связи иной формации, основанные на доверии и заинтересованности, сводящие на нет мотивы и стимулы к недобросовестному поведению.

Так как ключевой детерминантой спроса на рынках доверительных блага выступает доверие, то механизмы и инструменты борьбы с оппортунизмом на данном рынке должны быть ориентированы на повышение социального капитала общества путем наращивания доверия.

Социальный капитал представляет собой общественный ресурс, характеризующий потенциал социальных отношений в обществе в зависимости от присущих ему уровня доверия и взаимопомощи, развитости неформальных связей, норм и сигналов.

По определению Ф. Фукуямы, социальный капитал - это «определенный потенциал общества или его части, возникающий как результат наличия доверия между его членами» [7]. Доверие лежит в основе данного ресурса, представляя собой его структурное ядро, экономическая и общественная эффективность которого заключается в снижении трансакционных издержек и погашении оппортунистических настроений в процессе взаимодействия.

Обществам с высоким уровнем социального капитала присущи высокий уровень доверия между индивидами, легкость доступа к информации, наличие связей с агентами, принимающими решения или владеющими ресурсами, причастность агентов к системе общественных связей, позволяющая им формировать личный статус и положение в обществе, предсказуемость результата сделки за счет закрепившихся норм поведения, наличие благоприятного психологического климата.

Понятие «доверие» условно можно подразделить на два типа. Первое - это деперсонифицированное доверие [8], представляющее общие нормы, правила и убеждения, формирующие представления индивида о действительности, обусловливающие его модели поведения, позволяющие адаптироваться в социуме и принимать решения, по его мнению, минимизируя риски потерь.

Второе - это персонифицированное доверие, представляющее личные связи и отношения субъектов, позволяющие извлекать из них личную выгоду и получать доступ к ресурсам [8].

Когда взаимосвязи приобретают активное развитие в рамках отдельных групп агентов и носят локальный характер (персонифицированное доверие), выигрывает только ограниченное число агентов, что ведет к дисбалансу между субъектами общества, создавая стимулы к недобросовестным действиям и обостряя изучаемую нами проблему.

Если система связей приобретает массовый характер, образуя разветвленную основанную на доверии систему взаимоотношений (деперсонифицированное доверие), то это способно приносить положительную экономическую отдачу, минимизируя издержки взаимодействия, снижая уровень социального напряжения и увеличивая общественное благосостояние [9, с. 9].

Парадокс данной «двузначности» заключается в том, что достичь высокого уровня социального капитала общества за счет построения доверия на каком-то одном уровне, пренебрегая другим, не представляется возможным.

Если направить усилия на формирование персонифицированного доверия, то выгодоприобретателями будут только отдельные субъекты. Если сфокусировать усилия на повышении деперсонифицированного доверия, то высока вероятность навязывания норм и институтов «сверху» без наличия реальных органически сложившихся связей на уровне контрагентов. Поэтому ключевая задача 
на пути формирования социального капитала современного общества должна сводиться к укреплению сложившихся персонифицированных связей и наращиванию деперсонифицированного доверия.

С учетом выделенных уровней доверия понятие социального капитала целесообразно расширить, добавив к ядру данной категории два элемента: 1) нормы, убеждения и системы ценностей, являющиеся базой для построения деперсонифицированного доверия; 2) социальные связи и отношения между экономическими агентами, представляющие основу для персонифицированного доверия. Структура социального капитала представлена на рисунке.

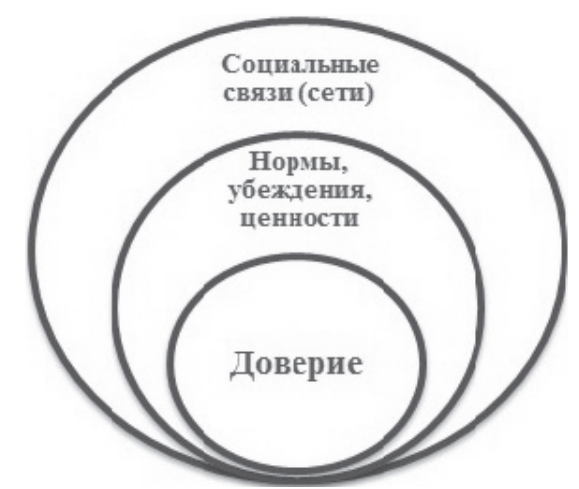

Рисунок. Структура социального капитала

Методологической отправной точкой изучения методов формирования доверия на рынках доверительных благ является определение субъекта и направлений (инструментов) его формирования на двух уровнях.

Субъектом формирования деперсонифицированного доверия на рынках доверительных благ, на наш взгляд, выступает государство.

Ключевыми направлениями формирования деперсонифицированного доверия на рынках доверительных благ являются следующие:

- повышение национального и индивидуального благосостояния населения с целью создания благоприятной социально-экономической основы для построения доверительных отношений;

- трансформация ценностных ориентаций с целью создания стимулов для построения духовной модели общества взамен на укрепившуюся в обществе конкурентную систему отношений;

- повышение степени доверия к государству и государственным институтам у членов общества.

Процесс формирования отношений, основанных на доверии, затруднителен в обществах, характеризующихся социальным неравенством, низким уровнем общественного благосостояния и качества жизни населения.
Настроения современного российского общества едва ли можно оценить как доброжелательные и открытые, что обусловлено серьезным разрывом в уровне благосостояниями между его гражданами.

По состоянию на 2016 г., согласно децильному коэффициенту фондов, дифференциация денежных доходов между 10 \% населения РФ с самыми высокими доходами и $10 \%$ с самыми низкими оценивалась в 15,7 раз. Коэффициент Джини в 2016 г. составлял 0,414 [10].

Согласно материалам доклада швейцарского банка Credit Suisse о глобальном богатстве за 2016 г. Россия была признана страной с самым большим имущественным неравенством: 1 \% населения принадлежит 74,5 \% национального богатства страны [11].

Россияне все чаще вынуждены придерживаться модели поведения, именуемой «стабильность жизни», пренебрегая такими ценностями и ориентирами, как «самореализация» и «духовность» [12].

Напряженная социально-экономическая обстановка современного общества проявляется в антагонизме, росте конфликтогенности и требует от государства больших усилий, направленных на повышение национального и индивидуального благосостояния населения.

Меры повышения национального благосостояния предполагают повышение уровня валового национального дохода на душу населения, снижение уровня инфляции и уровня безработицы. Ими являются повышение размеров оплаты труда, введение прогрессивной системы налогообложения, снижение или хотя бы замедление процесса роста тарифов ЖКХ, снижение ставок по кредитам, обеспечение беспрепятственного доступа к социальным благам.

Только реализовав данные меры, создав условия для нормального существования населения и стабилизировав настроения в обществе, можно предпринимать попытки для построения общественного уклада, основанного на доверительных связях между экономическими агентами.

Вторым направлением формирования деперсонифицированного доверия на рынках доверительных благ является создание стимулов для построения духовной модели общества взамен на укрепившуюся в обществе конкурентную систему отношений.

Категоричная смена ценностей, угасание нравственности, повышение стимулов к «ложным» целям повлекли ориентацию сугубо на материальные ценности, максимизацию индивидуальной 
полезности, эгоцентризм и расчетливость. Очевидно, что сформировавшиеся психологические барьеры между агентами и атомизация общества препятствуют возникновению и развитию связей между субъектами.

Попытки разрешения современного духовного кризиса мы видим в создании государством благоприятных условий для формирования обобщенного доверия и смены психоэмоциональных настроений в обществе. Все это, на наш взгляд, могло бы быть реализовано за счет мер, направленных на укрепление гражданской идентичности, создания условий для личностной самореализации индивидов, трансформации приоритетов образования.

Единая гражданская идентичность, национальное самосознание, чувство гордости и одновременно чувство ответственности за судьбу страны и народа должны быть положены в основу нового духовного общества.

Объединение и достижение сплоченности общества возможно путем формирования государственной идеологии как системы взглядов и ценностей, основанных и пропагандирующих духовное единство народа, общность, терпимость, честность и иные добродетели.

Личностная самореализация, наличие возможности реализовать свой профессиональный и творческий потенциал способствуют формированию здорового эмоционального фона индивида, благоприятствующего искреннему взаимодействию и стимулирующего труд высокого качества.

В реальной жизни все чаще приходится констатировать недостаток заинтересованности в результатах деятельности как со стороны руководства, так и стороны специалистов, отсутствие стимулов для саморазвития, безынициативность, профессиональную неудовлетворенность и риск недобросовестных действий.

Стимулировать иное отношение к труду могли бы, на наш взгляд, активное внедрение программ поддержки молодых специалистов, программы повышения квалификации специалистов, создание условий для сочетания практической и научной деятельности.

Институт образования, по нашему мнению, нуждается в трансформации за счет смещения акцентов в пользу развития духовных составляющих, уделения внимания таким дисциплинам, как история, литература, философия, религия, культурология, а также развития этического воспитания, психологии, делового общения, деонтологии.
Третье направление формирования деперсонифицированного доверия на рынках доверительных благ предполагает повышение степени доверия к государству и государственным институтам у членов общества. Наряду с усилиями государства по формированию доверия между членами общества не менее важным является формирование у членов общества доверия к нему самому.

Государству для формирования у членов общества доверительного отношения к себе необходимо, кроме создания и внедрения новых институтов, норм и ценностей, предпринять усилия для их принятия, адаптации и закрепления в обществе. А это, на наш взгляд, представляется возможным путем формирования государством чувства правовой защищенности у населения и усилиями государства по практическому подкреплению своими действиями новых отношений и устоев, основанных на доверии.

Формирование государством у населения чувства правовой защищенности подразумевает на рынках доверительных благ:

- развитие института компенсации морального вреда;

- закрепление и реализацию принципа неотвратимости наказания.

Содействие государства в решении и минимизации последствий морального вреда могло бы положительным образом сказаться на повышении чувства доверия, защищенности, ощущения государственного соучастия. В нашем понимании данные усилия предполагают спецификацию мер компенсации морального вреда, ранжирование штрафных санкций в зависимости от тяжести нанесенного вреда и специфики объекта трансакции, предоставление гарантий компенсации вреда потерпевшей стороне трансакции путем механизма принуждения субъектов, его нанесших. Наряду с этим закрепление принципа неотвратимости наказания и его реальное воплощение со стороны правоохранительных органов позволят сформировать уверенность среди субъектов рынка доверительных благ в их защищенности и равенстве перед законом.

Деятельность государства призвана в свою очередь стать для населения практическим примером добросовестного отношения и закрепления новых норм, ценностей, устоев, основанных на доверии.

Так как большая часть рентоориентированных действий скрыта от лица общества, в результате чего не представляется возможным проследить добросовестность поведения государства, то показательным примером могло бы стать снижение 
числа коррупционных действий при непосредственном взаимодействии индивидов с представителями власти. Это снижение случаев вымогательства, с которыми сталкиваются субъекты рынка при получении квот на медицинскую помощь или для целевого приема в вузы, для трудоустройства или получения разрешений на отдельные виды деятельности.

Если субъектом формирования деперсонифицированного доверия на рынках доверительных благ является государство, то формирование персонифицированного доверия является прерогативой субъектов предложения.

Ключевыми направлениями (инструментами) процесса формирования персонифицированного доверия на изучаемом рынке являются механизмы формирования высокой репутации субъекта предложения и механизмы развития и поддержания организационной культуры субъектов предложения.

Высокий уровень деперсонифицированного доверия в обществе является прочной основой для благоприятного взаимодействия, однако когда на рынках доверительных благ на кону стоят здоровье и жизнь индивида, его благополучие, безопасность, профессиональная деятельность и иные составляющие, то какими бы доброжелательными настроения ни были, потребителю всегда присуще сомнительность и настороженность.

Доверие на рынках, характеризующихся высокой степенью неопределенности, формируется на основании персонифицированного отношения потребителя к субъекту предложения, процессу и результату трансакции. Все это формирует и определяет рыночную репутацию субъекта предложения рынка доверительных благ. Причем в нашем понимании высокая репутация экономического агента не тождественна его высокому имиджу или успешному позиционированию себя в глазах своих потенциальных потребителей, а тождественна понятию «авторитет» и характеризуется такими ощущениями, как надежность, уверенность, доверительность.

Эффективность института репутации на рынках доверительных благ заключается в прямой зависимости: чем выше качество и добросовестность профессиональной деятельности субъектов предложения, тем выше их рыночная репутация и, как результат, выше устойчивые доверительные связи между контрагентами. Ярким примером подобной закономерности выступает сложившаяся на Западе положительная практика услуг семейных докторов, в основе взаимодействия с которыми лежат длительные доверительные отношения.
Формирование персонифицированного доверия также предполагает развитие и поддержание высокой организационной культуры субъектов предложения на рынке доверительных благ.

Если понятие «репутация» мы отождествляли с индивидуальными характеристиками субъекта - надежностью, уверенностью, доверительностью, то категория «организационная культура» ближе к таким коллективным характеристикам, как имидж, нормы поведения, правила, традиции, и таким эпитетам, как заинтересованность, открытость, активность.

Организационная культура субъектов предложения как инструмент психоэмоционального воздействия на восприятие доверительных благ призвана сформировать новые связи и отношения для построения персонифицированного доверия.

Процесс развития организационной культуры субъектов предложения на рынках доверительных благ предполагает:

- развитие института корпоративной культуры и делового общения;

- развитие института корпоративной социальной ответственности;

- разработку элементов и атрибутов визуального восприятия, фирменного стиля организаций.

Таким образом, антиоппортунистическим ресурсом на рынках доверительных благ, на наш взгляд, является социальный капитал, в основе которого лежит доверие между членами общества, а также нормы, убеждения и системы ценностей, формирующие деперсонифицированное доверие, и социальные связи и отношения между экономическими агентами, представляющие основу для персонифицированного доверия.

Для современного российского общества, характеризующегося низким уровнем обобщенного доверия и преобладанием персонифицированных отношений, необходимо укрепление сложившихся персонифицированных связей и формирование в полной мере не оформленного деперсонифицированного доверия.

Направлениями формирования деперсонифицированного доверия на рынках доверительных благ являются повышение национального и индивидуального благосостояния населения, трансформация ценностных ориентаций общества, повышение степени доверия к государству и государственным институтам у членов общества. Направлениями формирования персонифицированного доверия являются формирование высокой репутации субъекта предложения и развитие и поддержание организационной культуры субъектов предложения. 


\section{ЛИТЕРАТУРА}

1. Королев А. Тенденции оппортунистического поведения в условиях экономики неравновесности : дис. ... канд. экон. наук : 08.00.01 / А. Королев. - Саратов, 2007.$170 \mathrm{c}$.

2. Мартюкова Е. Оппортунизм и издержки оппортунистического поведения в российской экономике : идентификация и оценка : дис. ... канд. экон. наук : 08.00.01 / Е. Мартюкова. - СПб., 2013. - 201 с.

3. Попов Е. Оценка внутрифирменного оппортунизма работников и менеджеров / Е. Попов, В. Симонова // Проблемы теории и практики управления. - 2005. № 4. - С. 108-117.

4. Тупицыына М. Институциональная структура кредитного рынка : дис. ... канд. экон. наук : 08.00.01/ М. Тупицына. - СПб., 2008. - 195 с.

5. Колосова М. Анализ структуры рынка доверительных благ / М. Колосова // Вестник ОрелГИЭТ. 2016. - № 4 (38). - C. 174-179.

6. Колосова М. Специфика конкурентных отношений на рынке доверительных благ / М. Колосова // Научный форум : Экономика и менеджмент : материалы VII Междунар. науч.-практ. конф. - № 5 (7). - 2017. - С. 153-158.

7. Fukuyama F. Trust: the social virtues and the creation of prosperity / F. Fukuyama. - Moscow : AST. -2004. - 732 c.

Орловский государственный университет имени И. С. Тургенева

Скоблякова И. В., доктор экономических наук, профессор кафедры менеджмента и государственного управления

E-mail:ivs2510@mail.ru

Колосова М. А., соискатель кафедры менеджмента и государственного управления

E-mail: marykolosova@yandex.ru
8. Курбатова М. Структура социального капитала как фактор институционального развития региона / М. Курбатова, С. Левин, Е. Каган // Общественные науки и современность. -2010 . - № 6. - С. 37-51.

9. Колосова М. Роль социального капитала на рынках доверительных благ / М. Колосова // Современные проблемы и тенденции развития экономики и управления в XXI веке. - Липецк : Ра-Души, 2016. $196 \mathrm{c}$.

10. Материалы Федеральной службы государственной статистики. [1999-2017. Федеральная служба государственной статистики]. - URL: http://www.gks.ru/wps/ $\mathrm{wcm} /$ connect/rosstat_main/rosstat/ru/statistics/population/ poverty

11. All the world's most unequal countries revealed in one chart : материалы британского интернет-издания «The Independent». - URL: http://www.independent.co.uk/ news/world/politics/credit-suisse-global-wealth-worldmost-unequal-countries-revealed-a 7434431

12. Лебедева Н. Ценности и социальный капитал как основа социально-экономического развития / Н. Лебедева, А. Татарко // Journal of institutional studies (Журнал институциональных исследований). - 2010. - Т. 2 , № 1. - C. 17-34.

Orel State University named after I. S. Turgenev

Skoblyakova I. V., Doctor of Economics, Professor of the Department of Management and Public Administration

E-mail:ivs2510@mail.ru

Kolosova M. A., Researcher of the Department of Management and Public Administration

E-mail: marykolosova@yandex.ru 